\title{
PARADIGMA E ORDEM DO DISCURSO DA PESQUISA CONTÁBIL BRASILEIRA'
}

Paulo Frederico Homero Junior ${ }^{2}$

Resumo: Evidências sugerem que a pesquisa contábil brasileira passou por uma mudança de paradigma entre o final dos anos 1990 e início dos anos 2000, com a ascensão do positivismo em detrimento de abordagens normativas. Contudo, os estudos sobre este fenômeno têm se concentrado nas características metodológicas da produção analisada, embora a literatura pertinente defina os paradigmas como conjuntos de premissas subjacentes às escolhas metodológicas e compartilhadas por uma comunidade científica. Assim, o objetivo deste estudo é identificar quais são as premissas compartilhadas pela comunidade acadêmica brasileira, contribuindo para caracterizar o positivismo prevalente na pesquisa contábil nacional não apenas como um processo de homogeneização metodológica, mas também discursiva. Para tanto, propõe-se uma análise de 20 artigos sobre as International Financial Reporting Standards (IFRS), conduzida sob os pressupostos teórico-metodológicos da Análise Crítica do Discurso $(A C D)$, buscando-se reconstituir a ordem do discurso associada à prática social da pesquisa contábil no Brasil. Esta análise aponta a subordinação aos interesses da profissão contábil como principal característica do discurso da comunidade acadêmica nacional. Embora as limitações metodológicas não permitam alegar que tais resultados reflitam toda a diversidade da pesquisa contábil conduzida no Brasil, eles indicam que o positivismo prevalente na pesquisa contábil brasileira serve para que a comunidade acadêmica reafirme acriticamente interesses do campo profissional.

Palavras-chave: Análise Crítica do Discurso. Ordem do Discurso. Paradigma. Pesquisa Contábil. Positivismo.

\footnotetext{
Trabalho premiado como melhor trabalho na área de Educação e Pesquisa em Contabilidade no X Congresso Anpcont 2016 - Ribeirão Preto/SP.

${ }^{2}$ e-mail: paulo.junior@usp.br. Universidade de São Paulo 


\title{
PARADIGM AND ORDER OF DISCOURSE OF BRAZILIAN ACCOUNTING
} RESEARCH

\begin{abstract}
Evidences suggest that Brazilian accounting research went through a paradigm shift between the late-1990's and the early-2000's, with the rise of positivism in detriment of normative approaches. However, studies about this phenomenon have been focused on methodological characteristics of the production analyzed, even though the pertinent literature defines paradigms as sets of assumptions that underlie methodological choices and are shared by a scientific community. Thus, the objective of this study is to identify which the assumptions shared by the Brazilian academic community are, contributing to characterize the prevailing positivism of Brazilian accounting research not just as a process of methodological homogenization, but as a discursive homogenization as well. Therefore, an analysis of 20 articles about the International Financial Reporting Standards (IFRS) is proposed, made under the theoretical-methodological tenets of Critical Discourse Analysis (CDA), seeking to reconstitute the order of discourse associated to the social practice of accounting research in Brazil. This analysis points to the subordination to interests of the accounting profession as the main characteristic of the discourse of the national academic community. Albeit the methodological limitations do not allow to claim that these results reflect all the diversity of the accounting research conducted in Brazil, they indicate that the prevailing positivism of Brazilian accounting research serves for the academic community to uncritically reaffirm interests of the professional field.
\end{abstract}

Keywords: Critical Discourse Analysis. Order of Discourse. Paradigm. Accounting Research. Positivism. 


\section{INTRODUÇÃO}

- studos sobre a pesquisa contábil brasileira indicam ter havido uma mudança de paradigma dentre

-o final dos anos 1990 e início dos anos 2000, com o declínio de abordagens normativas e ascensão de abordagens positivas (Borges, Rodrigues, Silva, \& Santana, 2011; Cardoso, Oyadomari, \& Mendonça Neto, 2007; Theóphilo \& ludícibus, 2005). Porém, a identificação do paradigma positivista em tais estudos é feita apenas com base na uniformidade das escolhas metodológicas empregadas nas pesquisas analisadas, embora a literatura pertinente conceitue os paradigmas como conjuntos de premissas subjacentes a tais escolhas e compartilhadas por uma comunidade científica.

Assim, o objetivo deste artigo é identificar quais são as premissas compartilhadas pela comunidade acadêmica contábil brasileira, visando caracterizar, com base em tais nessas premissas, o paradigma prevalente nesta comunidade. Para tanto, busco suporte teórico-metodológico na Análise Crítica do Discurso (ACD) proposta por Fairclough (2010) para analisar os discursos que esta comunidade produziu sobre a convergência do Brasil às International Financial Reporting Standards (IFRS), um dos eventos de maior interesse ocorrido nas práticas contábeis nacionais desde que se deu a ascensão do paradigma positivista, buscando reconstituir a ordem do discurso prevalente em tal comunidade.

Trata-se de um recorte arbitrário, cuja principal finalidade foi a de viabilizar a execução desta pesquisa. No entanto, dada a escassez de estudos que discutam o(s) paradigma(s) de pesquisa na contabilidade brasileira sob a ótica das premissas compartilhadas pela comunidade acadêmica, este estudo contribui, em que pese seu caráter exploratório, para uma melhor caracterização do positivismo prevalente na pesquisa contábil nacional não apenas como um processo de homogeneização metodológica, mas também discursiva.

O artigo prossegue da seguinte maneira: na seção 2 discuto, a partir de revisão de literatura, o conceito de paradigma e a ascensão do positivismo na pesquisa contábil. Na seção 3 apresento as propostas teórico-metodológicas da ACD e os critérios que utilizei para definir o conjunto de textos analisados nesta pesquisa. Na seção 4 as premissas que identifiquei nestes textos são elencadas, acompanhadas por evidências que dão suporte a tal identificação. Por fim, na seção 5 sumarizo as principais conclusões do trabalho.

\section{PARADIGMAS E ASCENSÃO DO POSITIVISMO NA CONTABILIDADE}

O emprego do conceito de paradigma para analisar o desenvolvimento das ideias científicas tem origem no trabalho de Kuhn (1998). Para ele, paradigmas são "realizações científicas universalmente reconhecidas que, durante algum tempo, fornecem problemas e soluções modelares para uma comunidade de praticantes de uma ciência" (p. 13). No entendimento do autor, para constituírem um paradigma tais realizações devem ser suficientemente sem precedentes para atrair um grupo duradouro de partidários, mas também suficientemente abertas para deixar uma ampla gama de problemas a serem resolvidos pelos novos praticantes da ciência.

Como um conjunto de crenças teóricas e metodológicas interligadas e compartilhadas, um paradigma estabelece critérios para a identificação de problemas científicos relevantes e enseja a condução do que Kuhn (1998) batiza de ciência normal, ou seja, de uma agenda de pesquisas firmemente baseada 
em realizações científicas passadas, visando uma melhor articulação dos fenômenos e teorias prescritos pelo paradigma. No entanto, o autor também postula que a descoberta de fenômenos incompatíveis com o paradigma vigente leva a uma exploração destas anomalias, culminando em uma reformulação das premissas paradigmáticas de forma que o anômalo venha a se converter no esperado.

A repercussão da obra de Kuhn ultrapassou os limites da filosofia da ciência, ensejando debates em diversas outras disciplinas. Na área dos estudos organizacionais, por exemplo, Burrell e Morgan (1979) concebem os paradigmas como sendo definidos por premissas metateóricas que subscrevem os quadros de referência, os modos de teorização e o modus operandi dos cientistas que operam sob eles, ensejando perspectivas comuns que permitem considerá-los como uma abordagem da mesma problemática, mesmo sem implicar uma unidade completa de pensamento. Os autores sugerem que as teorias sociais podem ser classificadas segundo dois conjuntos de premissas: as sobre a natureza das ciências sociais, e as sobre a natureza da sociedade.

Quanto à natureza das ciências sociais, os autores identificam, conforme o conjunto de premissas ontológicas, epistemológicas, sobre a natureza humana e metodológicas adotadas, dois tipos distintos de abordagens: a subjetivista, que ressalta a importância das experiências subjetivas dos indivíduos na construção do mundo social, focando-se na relatividade de tais experiências; e a objetivista, que trata o mundo social como algo externo ao indivíduo, e portanto passível de ser descrito em termos de leis universais que expliquem e prevejam a realidade observada.

Já quanto à natureza da sociedade, Burrell e Morgan (1979) distinguem outras duas abordagens: a sociologia da regulação, composta por teorias que buscam explicar a sociedade em termos que enfatizam sua coesão e unidade subjacentes; e a sociologia da mudança radical, cuja ênfase é dada à procura por explicações para as mudanças radicais, para os conflitos estruturais, para os modos de dominação e de contradição estrutural percebidos como característicos das sociedades modernas. Com base nestes dois conjuntos de premissas, os autores identificam quatro paradigmas distintos nas ciências sociais, conforme indicado na Figura 1: humanismo radical, estruturalismo radical, interpretativo e funcionalista.



Figura 1: Quatro paradigmas para a análise das teorias sociais
Fonte: Adaptado de Burrell e Morgan $(1979$, p. 22).

O paradigma Funcionalista tende a assumir que o mundo social é composto por artefatos e relações empíricas relativamente concretas, que podem ser identificadas, estudadas e medidas através de abordagens derivadas das ciências naturais; o Interpretativo é baseado pela preocupação em entender o mundo como ele é, compreendendo a natureza fundamental do mundo social no nível das experiências subjetivas; o Humanismo Radical compartilha a abordagem interpretativista sobre o mundo social, mas é comprometido com uma visão de sociedade que enfatiza a importância de superar ou transcender as limitações dos arranjos sociais existentes; já o Estruturalismo Radical tem uma abordagem semeIhante à funcionalista, mas direcionada a fins fundamentalmente distintos, sendo comprometido com mudanças radicais, emancipação e potencialidades (Burrell \& Morgan, 1979). 
Enquanto Kuhn (1998) tem em mente a evolução das ciências naturais, e sobretudo da física, Burrell e Morgan (1979) se restringem às ciências sociais, e principalmente às análises organizacionais; enquanto Kuhn (1998) alude a paradigmas que se sucedem ao longo do tempo, com um novo paradigma reformulando os entendimentos dos anteriores ao suplantá-los, Burrell e Morgan (1979) descrevem paradigmas coexistentes e incomensuráveis entre si. Mas apesar destas distinções, ambos os modelos concebem os paradigmas como um conjunto de premissas subjacentes às atividades de uma comunidade científica, que tanto engendram uma agenda de pesquisas quanto limitam a gama de problemas identificáveis como passíveis de estudo.

Com base na noção de paradigma, alguns modelos têm sido propostos para classificar as pesquisas contábeis. Chua (1986), por exemplo, diferencia três perspectivas, de acordo com suas premissas subjacentes sobre o conhecimento, sobre os fenômenos empíricos e sobre a relação entre a teoria e o mundo prático, cujas características são descritas na Tabela 1.

Uma característica comum às discussões e classificações paradigmáticas das ciências é que, embora admitam a influência do ambiente social em que a ciência opera sobre a constituição e reformulação de paradigmas, este aspecto costuma ser negligenciado nas análises propostas, que se fixam em critérios internos à própria atividade científica. Uma alternativa teórica que supre esta lacuna, contribuindo para uma melhor compreensão sobre os processos que levam à reformulação dos paradigmas, é a análise sociológica proposta por Bourdieu (1976), para quem a verdade científica resulta de condições sociais de produção particulares, ou seja, da estrutura e do funcionamento do campo científico. Segundo o autor,

O universo "puro" da ciência mais "pura" é um campo social como qualquer outro, com suas relações de força e seus monopólios, suas lutas e suas estratégias, seus interesses e seus ganhos, mas onde todas estas características se revestem de formas específicas. (p. 89, tradução nossa).

No campo científico se dá uma disputa pelo monopólio da autoridade científica, entendida como a capacidade de falar e agir legitimamente em matéria de ciência. E a principal característica deste campo é que os produtores tendem, tanto mais quanto maior for a autonomia do campo, a não ter outros possíveis clientes que não seus próprios concorrentes. Bourdieu (1976) sustenta ainda que as ciências sociais enfrentam obstáculos maiores para sua autonomização, pois têm por objetivo a representação legítima do mundo social, que também é objeto de disputa no âmbito político da luta de classes. Desta forma, as classes dominantes buscam nas ciências sociais um reforço ao arsenal simbólico que legitima a ordem estabelecida, procurando convertê-las não em campos científicos, mas sim em campos produtores de discursos eruditos, caracterizados por uma estratégia de falsa ruptura que se vale de jargão erudito para reafirmar o senso comum.

Tabela 1: Premissas subjacentes às perspectivas da pesquisa contábil

\begin{tabular}{|c|c|c|c|}
\hline \multirow{2}{*}{ Abordagem } & \multicolumn{3}{|c|}{ Premissas } \\
\hline & Conhecimento & Realidade física e social & Relação entre teoria e prática \\
\hline Mainstream & $\begin{array}{c}\text { A teoria é independente das } \\
\text { observações que podem ser usadas } \\
\text { para verificá-la ou falsificá-la. Aceitação } \\
\text { do modelo hipotético-dedutivo de } \\
\text { explicação científica. }\end{array}$ & $\begin{array}{l}\text { A realidade empírica é objetiva e externa } \\
\text { aos sujeitos. Os seres humanos também são } \\
\text { caracterizados como objetos passivos, e não } \\
\text { como construtores da realidade social. }\end{array}$ & $\begin{array}{l}\text { A contabilidade especifica meios, e não } \\
\text { fins. Aceitação das estruturas sociais } \\
\text { existentes. }\end{array}$ \\
\hline Interpretativa & $\begin{array}{l}\text { Busca por explicações científicas sobre } \\
\text { as intenções humanas, que são avaliadas } \\
\text { pela consistência lógica, interpretação } \\
\text { subjetiva e concordância com o senso } \\
\text { comum dos agentes. }\end{array}$ & $\begin{array}{c}\text { A realidade social é emergente, criada } \\
\text { subjetivamente, e objetificada através da ação } \\
\text { humana. }\end{array}$ & $\begin{array}{l}\text { A teoria busca apenas explicar as ações } \\
\text { e entender como a ordem social é } \\
\text { produzida e reproduzida. }\end{array}$ \\
\hline Crítica & $\begin{array}{l}\text { Critérios para o julgamento de } \\
\text { teorias são limitados temporal e } \\
\text { contextualmente. }\end{array}$ & $\begin{array}{c}\text { A realidade empírica é caracterizada por } \\
\text { relações objetivas que são transformadas } \\
\text { e reproduzidas através de interpretações } \\
\text { subjetivas. }\end{array}$ & $\begin{array}{c}\text { A teoria tem um imperativo crítico: a } \\
\text { identificação e remoção da dominação e } \\
\text { de práticas ideológicas. }\end{array}$ \\
\hline
\end{tabular}


Na área contábil, a profissão é identificada na literatura internacional como uma importante fonte de influência externa ao campo científico (Baker \& Bettner, 1997; Gendron \& Bédard, 2001; Sikka, Willmott, \& Puxty, 1995), ainda que também sejam destacadas as atuações de outros grupos de interesse, como fundações empresariais (Chabrak, 2012; Chua, 1996; Wilkinson \& Durden, 2015) e o Estado (Humphrey \& Gendron, 2015). Embora Jeanjean e Ramirez (2009) sustentem que a ascensão do positivismo na contabilidade, iniciada nos Estados Unidos durante a década de 1960, tenha sido possibilitada pela dissociação entre a teoria e a prática contábil, engendrada pela geração de pesquisadores normativos precedente a esta emergência, Baker e Bettner (1997) sugerem que uma das possíveis razões para a ausência de pesquisas interpretativas e críticas nos principais periódicos dos Estados Unidos seja um vínculo estreito entre a academia e a profissão contábil: ao assumir uma postura "científica" e "neutra" em relação a valores, a pesquisa contábil evitaria perturbar os interesses da profissão.

Enquanto na pesquisa contábil estadunidense a ascensão do positivismo remonta ao final da década de 1960, no Brasil este processo se deu apenas dentre o final dos anos 1990 e início dos anos 2000. Embora vários autores identifiquem ter ocorrido uma mudança de paradigma nesse período (Borges et al., 2011; Cardoso et al., 2007; Theóphilo \& ludícibus, 2005), a literatura nacional ainda carece de análises que permitam compreender as razões de tal mudança. A tese de Martins (2012), porém, avança neste sentido, apontando a implementação do sistema de avaliação dos programas de pós-graduação pela Coordenação de Aperfeiçoamento de Pessoal de Nível Superior (CAPES) como um catalizador deste processo.

\section{ANÁLISE CRÍTICA DO DISCURSO: ASPECTOS TEÓRICO- METODOLÓGICOS}

De acordo com Gill (2002), há uma variedade de abordagens aos estudos textuais, desenvolvidas a partir de diferentes tradições teóricas, que são descritas como análise do discurso. Todas elas compartilham, porém, a visão de que a linguagem não apenas reflete, mas também constrói realidades sociais. Neste trabalho, tomo por base os pressupostos da ACD, na qual Fairclough (2010) identifica três propriedades básicas: ela é relacional, no sentido de que seu foco primário não é em entidades ou indivíduos, mas em relações sociais; ela é dialética, já que as relações entre o discurso e outros objetos como o mundo físico, pessoas, relações e instituições de poder são concebidas em termos de continuidade, nenhum deles sendo completamente separado dos outros; e ela é transdisciplinar, dado que analisa relações entre o discurso e outros objetos, atravessando limites convencionais entre disciplinas.

Para as práticas discursivas, entendidas como a produção, distribuição e consumo de textos, Fairclough (2010) sugere três categorias de análise: os gêneros - modos específicos de ação, de produção textual (por exemplo: artigo acadêmico, palestra, notícia jornalística, etc.); os estilos - modos de ser, de construir e expressar as identidades dos participantes de um evento discursivo; e os discursos - modos de representar o mundo, expressando os pontos de vista dos participantes.

O autor diferencia também a realidade social em três níveis abstratos: estruturas, práticas e eventos sociais. Estruturas sociais são concebidas como potencialidades seletivamente efetivadas em eventos sociais, e a relação entre estruturas e eventos é mediada pelas práticas sociais, que controlam a efetivação seletiva das potencialidades. A cada um destes níveis, Fairclough (2010) atribui uma dimensão semiótica, como indicado na Tabela 2. 
Tabela 2: Dimensões semióticas da realidade social

\begin{tabular}{cc}
\hline Nível da realidade social & Dimensão semiótica \\
\hline Estruturas sociais & Sistemas semióticos (línguas) \\
\hline Práticas sociais & Ordens do discurso \\
\hline Eventos sociais & $\begin{array}{c}\text { Textos (incluindo conversas, } \\
\text { enunciações) }\end{array}$ \\
\hline Nota. Fonte: Adaptado de Fairclough (2010)..
\end{tabular}

Ao discorrer sobre as ordens do discurso, Foucault (1999) sustenta a hipótese de que "em toda sociedade a produção do discurso é ao mesmo tempo controlada, selecionada, organizada e redistribuída por certo número de procedimentos que têm por função conjurar seus poderes e perigos, dominar seu acontecimento aleatório, esquivar sua pesada e temível materialidade" (pp. 8-9). Adaptando tal conceito, Fairclough (2010) define as ordens do discurso como a estruturação social das variações ou diferenças semióticas: uma configuração específica de discursos, gêneros e estilos que atua como um mecanismo de filtragem entre o que é semioticamente possível, dados os sistemas semióticos, e as características semióticas efetivas dos textos, ou, em outras palavras, entre o que é possível dizer e o que é dito de fato.

Assim, considerando as ordens do discurso como o momento semiótico/discursivo das práticas sociais, e tendo em vista o entendimento dos paradigmas como um conjunto articulado de premissas compartilhadas por uma comunidade científica, conforme discutido na seção 2, proponho neste estudo uma análise do(s) discurso(s) produzido pela comunidade acadêmica brasileira sobre as IFRS, visando identificar na sua ordem do discurso as premissas do paradigma sob o qual se dá a prática social da pesquisa contábil no Brasil.

Para conduzir esta investigação, adoto uma lógica abdutiva ou retrodutiva, pela qual se observam fatos ou anomalias e então se tenta determinar o que pode tê-los causado, produzindo uma hipótese plausível e a confrontando com alternativas para encontrar uma explicação adequada. Diferentemente da indução, a retrodução não busca generalizações baseadas em inferências a partir de regularidades empíricas; ao invés disso, busca prover explicações razoáveis para os problemas de pesquisa analisados. Para Glynos e Howarth (2007), a retrodução compreende três momentos interconexos: a problematização de fenômenos empíricos, a explicação retrodutiva destes fenômenos, e a persuasão da comunidade acadêmica e demais atores interessados.

A limitação a pesquisas sobre as IFRS tem um caráter essencialmente pragmático, visando restringir o conjunto de textos a uma quantidade factível de ser analisada. Com o mesmo intuito, a seleção dos textos incluiu apenas artigos científicos, de autores brasileiros, identificados nas bases de dados Scopus e Web of Science através de buscas pelo termo IFRS em 03/02/2016. Dos 25 textos apontados nas buscas em ambas as bases de dados, não consegui obter acesso a 3 e optei por excluir outros 2 , pois investigavam problemas específicos de outros países.

$\mathrm{Na}$ leitura dos 20 textos assim selecionados, destaquei as passagens que evidenciavam os discursos, ou seja, as representações de mundo e pontos de vista, a respeito da contabilidade. Neste processo de leitura identifiquei 8 proposições que representam os argumentos mais recorrentemente empregados. As passagens destacadas em cada texto foram categorizadas de acordo com tais proposições, que são indicativas da ordem do discurso da comunidade acadêmica brasileira, representando premissas adotadas em suas práticas de pesquisa. Na seleção dos excertos apresentados na seção 4 procurei apresentar aqueles que melhor representassem cada categoria, mas tendo o cuidado de incluir ao longo da seção ao menos uma passagem de cada um dos 20 textos. 
Ao utilizar tais critérios de recorte, e não outros, parti da premissa, questionável, de que o tema e as bases de dados escolhidas são representativos em relação aos discursos produzidos pela comunidade acadêmica contábil brasileira em geral. Mas não há dúvidas de que tais restrições limitam a abrangência dos resultados apresentados na seção 4, que podem ser tomados como indicativos, mas não como uma descrição completa da ordem do discurso desta comunidade. Ademais, o próprio conceito de ordem do discurso não pressupõe um determinismo completo em relação aos textos, sendo esperadas dissonâncias e mesmo disputas nas práticas discursivas de uma comunidade, e as principais dissonâncias que identifiquei em relação ao discurso dominante dentre estes 20 textos, também reportadas na seção 4, corroboram o caráter preliminar dos resultados apresentados.

\section{DISCURSO ACADÊMICO BRASILEIRO SOBRE AS IFRS}

A Tabela 3 identifica os 20 artigos que analisei. Seguindo proposta de Gendron e Baker (2005), classifiquei suas abordagens como positivista ou sociológica, esta última caracterizada pela falta de hipóteses formais e/ou análises quantitativas de dados oriundos de levantamentos ou métodos experimentais. Além disso, sumarizei também a metodologia e o tema abordado em cada um deles. Tais classificações evidenciam um predomínio de pesquisas do tipo archival com abordagem positivista, corroborando as sugestões de que a pesquisa contábil brasileira opera sob um paradigma positivista. Nas subseções seguintes, dedico-me a analisar os discursos deste conjunto de textos, identificando as premissas compartilhadas pela comunidade acadêmica brasileira.

Tabela 3: Abordagens, metodologias e tópicos de pesquisas brasileiras sobre as IFRS

\begin{tabular}{|c|c|c|c|}
\hline Referência & Abordagem & Metodologiaa & Tópico \\
\hline Almeida e Lemes (2013) & Positivista & Levantamento & Práticas contábeis \\
\hline Calvi e Galdi (2014) & Positivista & Archival & Value relevance \\
\hline Cardoso, Saravia, Tenório e Silva (2009) & Sociológica & Ensaio teórico & Regulação contábil \\
\hline Carmo, Ribeiro e Carvalho (2011) & Positivista & Documental & Regulação contábil \\
\hline Carvalho e Salotti (2013) & Sociológica & Narrativa Pessoal & Educação contábil \\
\hline Chiqueto, Silva, Colossal e Carvalho (2015) & Positivista & Archival & Value relevance \\
\hline Lemes e Carvalho (2009) & Positivista & Archival & Comparabilidade \\
\hline Lopes e Walker (2012) & Positivista & Archival & Escolhas contábeis \\
\hline Oliveira e Lemes (2011) & Positivista & Documental & Disclosure \\
\hline Pelucio-Grecco, Geron, Grecco e Lima (2014) & Positivista & Archival & Gerenciamento de resultados \\
\hline Pimentel (2015) & Positivista & Archival & Value relevance \\
\hline Pires e Decourt (2015) & Positivista & Archival & Qualidade dos resultados \\
\hline L. L. Rodrigues, Schmidt e Santos (2012) & Sociológica & Documental & Regulação contábil \\
\hline M. M. Rodrigues, Hein, Wilhelm e Kroenke (2015) & Positivista & Archival & Qualidade dos resultados \\
\hline E. S. Santos e Calixto (2010) & Positivista & Archival & Compliance e conservadorismo \\
\hline E. S. Santos, Ponte e Mapurunga (2014) & Positivista & Documental & Compliance \\
\hline L. P. G. dos Santos, Lima, Freitas e Lima (2011) & Positivista & Archival & Conservadorismo \\
\hline M. A. C. dos Santos e Cavalcante (2014) & Positivista & Archival & Value relevance \\
\hline O. M. dos Santos e Santos (2014) & Positivista & Documental & Regulação contábil \\
\hline Souza, Botinha, Silva e Lemes (2015) & Positivista & Archival & $\begin{array}{l}\text { Comparabilidade e escolhas } \\
\text { contábeis }\end{array}$ \\
\hline
\end{tabular}




\subsection{O DISCURSO DOMINANTE}

O alto nível de homogeneidade epistemológica e metodológica dos artigos analisados, tal qual evidenciado na Tabela 3, indica que o gênero textual escolhido para análise apresenta pouca variabilidade, o que acaba se refletindo também nos discursos apresentados nestes textos. A ordem do discurso que emerge da análise destes artigos pode ser resumida em algumas proposições, que serão exploradas nas próximas subseções.

\subsubsection{O Mercado de Capitais é o Contexto Mais Relevante em que a Contabilidade Opera}

Dos 20 artigos que analisei, 13 estudam amostras de companhias listadas na BM\&FBovespa. Embora a disponibilidade pública de dados relativos a estas companhias facilite a condução de tais pesquisas, ao se restringir a estes dados a comunidade acadêmica acaba negligenciando outros contextos nos quais a contabilidade desempenha papel relevante e a adoção das IFRS pode também ter causado impactos significativos, tais como o mercado de crédito, a administração tributária, os litígios judiciais, o mercado de trabalho contábil, etc.

Esta restrição no foco das pesquisas se torna ainda mais problemática se considerarmos a baixa relevância do mercado de capitais como fonte de financiamento e alternativa de investimento na economia brasileira. Dados disponibilizados pelo Banco Central do Brasil (2017), por exemplo, indicam que a média anual de desembolsos do Banco Nacional de Desenvolvimento Econômico e Social (BNDES) entre 1995 e 2015, de R\$ 7,6 bi, por si só já supera a média anual das emissões primárias no mesmo período, que foi de apenas R\$4,2 bi. Dados da BM\&FBovespa (2016), por sua vez, indicam que ao final de 2015 somente 557.109 investidores pessoa física possuíam ações ou outros ativos registrados na bolsa, o que equivale a menos de 0,3\% da população residente no Brasil em 2015, de 204.450.649 pessoas, conforme projeção do Instituto Brasileiro de Geografia e Estatística (2016). A despeito disso, o mercado de capitais é tomado como único parâmetro para atestar a relevância da contabilidade, ainda que a relevância do mercado de capitais brasileiro em si seja passível de questionamentos.

\subsubsection{A Contabilidade Tem um Propósito: Fornecer Informações Úteis aos Investidores}

O propósito declarado pelos reguladores de que a contabilidade deva fornecer informações úteis a seus usuários é tratado como um dogma, ainda que tal ideia tenha iniciado a se consolidar no pensamento contábil apenas a partir da década de 1960, no contexto estadunidense em que a profissão visava escapar à intervenção estatal direta sobre a regulação contábil e precisava, para isso, fortalecer sua imagem de comprometimento com o interesse público (Young, 2006).

Chama atenção o modo reificado como a contabilidade é tratada, como se ela própria tivesse um propósito intrínseco, ao invés de ser uma prática social levada a cabo por agentes que, estes sim, sejam dotados de propósitos. Além disso, assume-se um propósito singular: fornecer informações úteis aos usuários. Outras finalidades das práticas contábeis discutidas na literatura internacional, como sua dimensão retórica (Carruthers \& Espeland, 1991), seu papel na construção da realidade social (Hines, 1988, 1991) e no controle da força de trabalho (Bryer, 2006), por exemplo, são ignoradas.

A contabilidade é considerada a linguagem global no mundo dos negócios e seus objetivos, conforme ludícibus, Martins e Carvalho (2005), decorrem, sobretudo, das necessidades de seus usuários. Ela tem por finalidade atender os usuários com informações relevantes, úteis e em tempo hábil, as quais serão utilizadas para controle, planejamento, avaliação e tomada de decisão. (Oliveira \& Lemes, 2011, pp. 157-158). ${ }^{2}$ 
A informação contábil tem que lidar com um trade-off entre relevância e confiabilidade. Por um lado a contabilidade tem que fornecer uma informação relevante que permita o seu usuário utilizá-la na sua formação de opinião e tomada de decisão. Por outro lado a informação deve ser confiável e não estar à mercê de viés de quem a prepara. (Pires \& Decourt, 2015, p. 741).

Mas mesmo este propósito singular é descrito em termos restritos, já que não se trata de atender aos interesses de qualquer usuário interessado, mas apenas e tão somente aos dos investidores. Trata-se, uma vez mais, de uma reprodução acrítica do discurso limitado e limitante que os reguladores expressam sobre a contabilidade.

Conjuntamente, esses resultados sugerem que a adoção dos IFRS não aumentou a relevância informacional do lucro contábil para os participantes do mercado, constatação que, em princípio, vai de encontro ao objetivo fundamental desses padrões: fornecer informações úteis à tomada de decisão dos investidores. (M. A. C. dos Santos \& Cavalcante, 2014, p. 240)

Para que seja possível a escolha entre as alternativas de investimentos, a contabilidade, por meio de seus relatórios contábeis, subsidia os investidores com informações úteis e relevantes para a escolha de tais alternativas. (Oliveira \& Lemes, 2011, p. 156).

Além disso, os investidores são caracterizados de maneira homogênea, como se não houvesse distinções relevantes entre eles: nacionais e estrangeiros, institucionais e individuais, todos eles são descritos não de acordo com referências a evidências empíricas de seus comportamentos, mas sim a prescrições oriundas de modelos teóricos sobre como devam se comportar.

Dessa forma, a comparabilidade das informações produzidas pela contabilidade torna-se relevante no contexto dessas escolhas, considerando que ela é a base para a tomada de decisão por parte dos investidores sobre em qual empreendimento empregar seu capital. (Oliveira \& Lemes, 2011, p. 156).

Em consonância com o Modelo de Precificação de Ativos Financeiros (CAPM), E(Rit+T) aumenta de acordo com o risco sistemático. Consequentemente, riscos (sistemáticos) elevados devem estar relacionados com baixos ERCs, sugerindo uma relação negativa entre esses parâmetros. A lógica por trás da relação negativa é que quanto mais arriscados forem os retornos futuros esperados pela firma, menor será o valor dessa firma para um investidor avesso ao risco. (Pimentel, 2015, p. 292).

A escolha lexical também é indicativa de uma visão comprometida com os mercados de capitais: o termo investidor, sugerindo um corajoso tomador de riscos que beneficia a todos os demais agentes econômicos, é o mais extensivamente utilizado, enquanto o neutro acionista raramente é empregado. Rentista ou especulador não ocorrem nos textos que analisei.

\subsubsection{Os Investidores Tomam Decisões com Base em Informações Contábeis}

A principal justificativa para que a contabilidade tenha o propósito de fornecer informações úteis aos investidores é que eles tomam decisões com base em informações contábeis. Esta premissa está por trás dos diversos estudos que buscam associações estatísticas entre informações contábeis e cotações de ações. Porém, como Burchell, Clubb, Hopwood, Hughes e Nahapiet (1980) já destacavam há longo tempo, trata-se de uma premissa mais assumida do que descrita: os preços das ações são a única evidência de comportamento dos investidores analisada; os processos pelos quais as informações contábeis são incorporadas às decisões dos investidores são largamente ignorados.

Este estudo torna-se relevante por propiciar a investigação da reação do mercado com relação a um posicionamento específico do normatizador contábil internacional (IASB)..... A segunda consequência é relacionada com o uso da informação contábil nos modelos de avaliação de ações pelos investidores. Uma reação do mercado à carta do IASB significa que os números contábeis são efetivamente utilizados nos modelos de precificação. (Calvi \& Galdi, 2014, pp. 80-81).

Entre as características que imputam utilidade à informação contábil divulgada, a confiabilidade é uma das que mais se destaca. É a partir desse atributo que os agentes econômicos avaliam e formam sua própria opinião sobre se o que está contido nas 
demonstrações, de fato, representa a realidade econômica, financeira e patrimonial da entidade que está sendo reportada. (L. P. G. dos Santos et al., 2011, p. 176).

\title{
4.1.4 Os Investidores Monitoram os Gestores com Base em Informações Contábeis
}

Uma justificativa secundária para que o propósito da contabilidade seja fornecer informações úteis aos investidores é de que eles as utilizam para monitorar o comportamento dos gestores. Este comportamento é caracterizado, também de maneira homogênea, como sendo moldado pela busca de satisfação a interesses pessoais dos gestores, que são apontados como os responsáveis pelas escolhas contábeis. Uma vez mais, tratam-se de premissas amparadas não em evidências sobre os processos efetivamente empregados nas organizações, mas em modelos teóricos que prescrevem este comportamento e ignoram a influência da profissão contábil sobre tais processos.

\begin{abstract}
Alinhando as escolhas contábeis com o processo de regulação contábil, os gestores teriam incentivos econômicos para realizar lobbying contra ou a favor de uma regulamentação contábil de modo a tentar influenciar o órgão emissor a optar por modelos contábeis que lhes permitam, por exemplo: reduzir ou diferir o pagamento de tributos; diminuir os custos políticos e a produção de informações (divulgação); ou aumentar o recebimento de bônus. (O. M. dos Santos \& Santos, 2014, p. 127).

Em referência às características das empresas percebidas como fatores explicativos às escolhas contábeis dos gestores, identificou-se que big four, país, endividamento, relevância do saldo de PPI e lucro líquido apresentaram índices estatisticamente significativos, ou seja, influenciam a escolha dos gestores em relação à avaliação posterior de PPI. (Souza et al., 2015, p. 165).
\end{abstract}

\subsubsection{Os Reguladores e a Profissão Contábil Atuam para Proteger os Interesses dos Investidores}

Ao contrário da suspeição com que se descrevem os comportamentos dos gestores, os reguladores e a profissão contábil são representados como agentes desinteressados, que não atuam senão para proteger os investidores, e seus propósitos autodeclarados são reproduzidos sem questionamento.

Besides the restrictive role that accounting regulation plays for earnings management, the importance of independent auditing is emphasized. The auditor has the responsibility to verify if the financial and patrimonial position disclosed by an entity is represented reliably. According to Santos and Grateron (2003), 'In the accounting information external users and even the clients' point of view, the auditor's acting is a synonym of trust and credibility.' (Pelucio-Grecco et al., 2014, p. 43).

.... é um aspecto positivo, pois serve como um indício de que as opiniões dos profissionais ligados à contabilidade ao redor do mundo convergem para um objetivo comum, que é o aumento da qualidade dos relatórios financeiros, facilitando, assim, o processo de convergência de fato que é o principal objetivo das normas internacionais. (Carmo et al., 2011, p. 260).

Dentre esses órgãos, aquele que tem, nos últimos 20 anos, se mantido e se fortalecido, como condutor do processo de convergência para uma linguagem contábil mundial única, é o IASB, um órgão independente que tem por objetivo promover a aprovação e adoção de normas contábeis que sejam usadas por empresas e outras organizações na preparação de demonstrações financeiras em âmbito mundial. (Lemes \& Carvalho, 2009, p. 26).

\subsubsection{O Estado Não Deve Interferir nas Decisões Regulatórias}

A visão laudatória da regulação contábil é estendida apenas aos normatizadores "independentes", isto é, entidades privadas que congregam representantes dos principais interessados nesta regulação, e que excluem de seus processos decisórios quaisquer considerações alheias aos mercados de capitais. Interferências estatais sobre tais processos são consideradas indevidas, devendo o Estado delegar o poder decisório aos próprios regulados.

O Brasil é um país que conta com um sistema jurídico codificado e extremamente legalista (code law). Antes da convergência, as normas contábeis sofriam forte influência dos ditames legais, em especial da legislação tributária, e da regulamentação proveniente de organismos governamentais, tais como o Banco Central do Brasil (BC) e a Comissão 
de Valores Mobiliários (CVM) (Dantas, Rodrigues, Niyama, \& Mendes, 2010; Niyama, 2007). (M. A. C. dos Santos \& Cavalcante, 2014, p. 230).

For more than a century, accounting practices and the "culture of accounting" in Brazil were tax-oriented. Tax requirements imposed severe restrictions on what could and should be deducted for tax purposes, and on what and when revenues and earnings could and should be deferred or taxed. These strict requirements guided business decisions. .... All this changed with the country's convergence toward IFRS. Leading players and stakeholders in the business game realized that tax and financial accounting should and could be separated from each other, with financial reporting aimed at the objective of informing users about the expected cash flows from an entity's operations and not distorted by tax limitations. (Carvalho \& Salotti, 2013, pp. 237-238).

\title{
4.1.7 O Estado Deve Fazer Cumprir as Decisões Regulatórias
}

Embora se renegue a participação do Estado no processo de elaboração das normas contábeis, seu poder é requerido para implementar as decisões tomadas pelos normatizadores "independentes". Curiosamente, parece haver pouca confiança no mercado para o desempenho desta tarefa. Além de subcontratar seu poder decisório, o Estado deve subordinar seu poder coercitivo aos desígnios da regulação privada, fazendo cumprir decisões sobre as quais não deve influir.

\begin{abstract}
Notably, IFRS adoption represented a reduction of earnings management. This advance improves investors' trust in Brazil and could cause more influx of foreign investments. We would also note that enforcement for regulatory agency is an important factor to restrict earnings management at least in legislative law countries such as Brazil. (Pelucio-Grecco et al., 2014, p. 44).

Isso significa que, no mercado informacional global, a conformidade com a divulgação requerida pelo IFRS, independentemente do (sempre necessário) enforcement, mostra-se uma escolha competitiva da empresa para obter os mesmos benefícios de mercado que tornam atrativa a adoção voluntária do IFRS. (E. S. Santos et al., 2014, p. 163).
\end{abstract}

\subsubsection{Inferioridade Brasileira}

As descrições do contexto brasileiro são em tom predominantemente depreciativo. Diferenças em relação a contextos externos são expostas como defeitos: o fato do mercado de capitais ser pouco desenvolvido no país é visto como uma deficiência, mesmo que o pequeno número de países nos quais estes mercados sejam desenvolvidos faça deles a exceção; a tradição do direito civil é representada em condição de inferioridade, advogando-se pela necessidade de uma "evolução" para a mentalidade do direito consuetudinário; e as normas contábeis anteriormente vigentes no país são consideradas de qualidade inferior, caracterizando como indiscutíveis os benefícios da convergência para as IFRS, tidas como de "alta qualidade".

The Brazilian financial reporting environment during the period covered in this study could be characterised as inimical to the production of high quality accounting reports. The strong influence of tax rules on financial reports, the low participation of the private sector and of the accounting profession in standard setting, and highly concentrated insider share ownership are the main examples of factors which reduced the informativeness of accounting reports. (Lopes \& Walker, 2012, p. 54).

Contrapondo-se à tradição formalista brasileira, o fundamento consuetudinário do padrão IFRS, ao priorizar a essência sobre a forma, o julgamento da realidade econômica sobre a mera desincumbência normativa e a transparência para o investidor, certamente representará profunda transformação na contabilidade, no perfil de seus profissionais e em seu currículo disciplinar. (E. S. Santos \& Calixto, 2010, p. 3).

\subsection{DISCURSOS DISSONANTES}

As proposições discutidas na seção 4.1 representam uma tentativa de reconstituir a ordem do discurso da academia contábil brasileira, a partir da análise dos artigos selecionados para esta pesquisa. Ainda que esta análise sugira um alto grau de homogeneidade na ordem do discurso investigada, é provável que em cada texto individual também se possam identificar elementos dissonantes. Neste 
sentido, quatro textos em particular me chamaram atenção, apresentando elementos que vão de encontro à ordem do discurso da área. Contudo, mesmo nestes casos o que se percebe são tentativas não de confronto, mas sim de reformulação do discurso dominante.

Cardoso et al. (2009), por exemplo, percebendo que"os livros de teoria da contabilidade não discutem as teorias da regulação, muito menos como tais teorias se aplicam à regulação da contabilidade" (p. 775), buscam subsídios em cinco diferentes teorias da regulação para entender o processo brasileiro de convergência às IFRS, fugindo da mera reprodução do discurso dos reguladores sobre si mesmos.

O. M. dos Santos e Santos (2014) também admitem que os reguladores tenham uma agenda de interesses próprios, podendo "adotar estratégias visando à manutenção do seu poder, da credibilidade perante a comunidade ou da reeleição dos seus membros" (p. 128). Mas apesar disso, em sua investigação sobre o lobbying na regulação contábil os autores levam em conta apenas os possíveis interesses das empresas que estariam sujeitas à regulação proposta pelo normatizador.

L. L. Rodrigues et al. (2012), por sua vez, em narrativa sobre a evolução histórica da regulação contábil brasileira, reconhecem a existência de conflitos, insatisfações e resistências à convergência do país às IFRS, o que é geralmente negligenciado nas descrições deste processo. Porém, trata-se de um aspecto minimizado pelos autores, que também adotam um tom triunfalista e sustentam a tese da inevitabilidade desta convergência.

Por fim, no que pode ser interpretado como uma dissonância de gênero dentre os 20 textos selecionados, apenas Almeida e Lemes (2013) levantam evidências junto a profissionais da área para sustentar suas investigações, não se limitando a analisar os produtos, mas considerando também os processos contábeis. Em que pesem as limitações metodológicas do trabalho, as autoras obtêm resultados que Ihes permitiriam questionar a alegada "alta qualidade" das IFRS, apontando sua ambiguidade e possível incapacidade de promover a padronização das práticas contábeis, apresentada como principal justificativa para sua expansão internacional. Contudo, as divergências de interpretação de normas por parte dos profissionais consultados são analisadas pelas autoras em função apenas de características dos próprios profissionais, sem que as normas em si sejam objeto de crítica.

\section{CONCLUSÕES}

Até o momento, os trabalhos que identificam na ascensão do positivismo uma mudança de paradigma na pesquisa contábil brasileira a descrevem sobretudo em termos das características metodológicas da produção científica analisada. No entanto, a literatura define os paradigmas como conjuntos de premissas subjacentes às escolhas metodológicas e compartilhadas por uma comunidade científica. Neste artigo procurei identificar, através da análise de artigos científicos sobre as IFRS, as principais premissas adotadas pela comunidade acadêmica brasileira, reconstituindo a ordem do discurso associada à prática social da pesquisa contábil no Brasil.

Minha análise sugere que no discurso da comunidade acadêmica nacional predomina uma visão neoliberal, marcada pelo compromisso com a expansão dos mercados de capitais e a não interferência estatal. Porém, a principal característica deste discurso é sua subordinação aos interesses da profissão contábil: a regulação privada da contabilidade, sob controle de normatizadores "independentes", é defendida em tom militante, e tais normatizadores, assim como a profissão, são representados de maneira acrítica, que simplesmente reproduz seus propósitos autodeclarados. 
Num aparente paradoxo, esta subordinação discursiva é acompanhada de um distanciamento metodológico em relação à prática contábil. Em geral, apenas os resultados de tais práticas são analisados, sem que haja qualquer investigação sobre os processos que levam a eles. Ao invés disso, os autores recorrem a modelos teóricos que prescrevem como tais processos devam ser, fazendo com que suas pesquisas assumam um caráter altamente normativo, a despeito das alegações de que o positivismo representaria uma ruptura com a tradição normativa que o precedeu na pesquisa contábil.

Contudo, uma única exceção identificada dentre os artigos que analisei, no qual as autoras buscam evidências diretamente junto a profissionais da área, demonstra que isto pode oferecer subsídios relevantes para que se questionem os fundamentos da normatização contábil, o que talvez explique o baixo emprego deste tipo de abordagem metodológica. Desta maneira, no caso específico do tema selecionado para a condução desta pesquisa, a prevalência de um único paradigma de pesquisa na comunidade acadêmica contábil brasileira, sugerida pela alta homogeneidade discursiva identificada, acaba limitando as possibilidades de investigação e de compreensão sobre o processo de convergência às IFRS ocorrido no país, cuja descrição é pautada por racionalizações providas pelos próprios agentes responsáveis pela convergência.

Os critérios de recorte adotados evidentemente limitam a abrangência destes resultados, que podem ser tomados como indicativos, mas não como uma descrição completa da ordem do discurso prevalente na comunidade acadêmica contábil brasileira. Assim, não posso alegar que as premissas identificadas nesta análise reflitam toda a diversidade da pesquisa contábil conduzida no Brasil, e nem tampouco das sobre as IFRS, haja vista a restrição a apenas 20 textos. Estudos que ampliem a base de textos analisada, que tenham enfoque em outros temas, que analisem a relação entre gênero e discurso, que abranjam outros gêneros discursivos e que levem em conta aspectos estilísticos poderão contribuir para um mapeamento mais abrangente. Além disso, mapeamentos da ordem do discurso prevalente na comunidade acadêmica contábil brasileira antes da ascensão do positivismo podem contribuir para que melhor se avalie a amplitude desta mudança paradigmática, que talvez tenha representado apenas a adoção de novos gêneros e estilos para se continuar reafirmando discursos subordinados a interesses do campo profissional. Isto corroboraria a sugestão de que tal comunidade constitui-se não como um campo científico, mas sim como um campo produtor de discursos eruditos.

\section{REFERÊNCIAS}

Baker, C. R., \& Bettner, M. S. (1997). Interpretive and critical research in accounting: a commentary on its absence from mainstream accounting research. Critical Perspectives on Accounting, 8(4), $293-310$. doi: $10.1006 /$ cpac.1996.0116

Banco Central do Brasil. (2017). Sistema Gerenciador de Séries Temporais. Recuperado em 18 de janeiro, 2017, de https://www3.bcb.gov.br/sgspub/localizarseries/localizarSeries.do?method=prepararTelaLocalizarSeries

BM\&FBovespa. (2016). Histórico pessoas físicas. Recuperado em 19 de janeiro, 2017, de http://www. bmfbovespa.com.br/pt_br/servicos/market-data/consultas/historico-pessoas-fisicas/

Borges, E. F., Rodrigues, J. M., Silva, C. A. T., \& Santana, C. M. (2011). Paradigmas na pesquisa contábil no brasil: um estudo epistemológico sobre a evolução nos trabalhos de programas de pós-graduação em ciências contábeis. ConTexto, 11(19), 21-30. doi: 10.1073/pnas.0703993104

Bourdieu, P. (1976). Le champ scientifique. Actes de la Recherche en Sciences Sociales, 2, 88-104. doi: 10.3406/arss.1976.3454

Burrell, G., \& Morgan, G. (1979). Sociological paradigms and organisational analysis: elements of the sociology of corporate life. Aldershot, UK: Ashgate. doi: 10.1177/003803858001400219. 
Cardoso, R. L., Oyadomari, J. C. T., \& Mendonça Neto, O. R. (2007). Influências da positive accounting nos programas de mestrado em contabilidade: uma análise bibliométrica da produção acadêmica de 2002 a 2005. Brazilian Business Review, 4(2), 158-170.

Chabrak, N. (2012). Money talks: the language of the Rochester School. Accounting, Auditing \& Accountability Journal, 25(3), 452-485. doi: 10.1108/09513571211209608

Chua, W. F. (1986). Radical developments in accounting thought. The Accounting Review, 61 (4), 601-632. doi: $10.2307 / 247360$

Chua, W. F. (1996). Teaching and learning only the language of numbers: monolingualism in a multilingual world. Critical Perspectives on Accounting, 7(1), 129-156. doi: 10.1006/cpac.1996.0019

Fairclough, N. (2010). Critical discourse analysis: the critical study of language (2nd ed.). New York: Routledge.

Foucault, M. (1999). A ordem do discurso: aula inaugural no Collège de France, pronunciada em 2 de dezembro de 1970. (L. F. de A. Sampaio, Trad.) (5a ed.). São Paulo: Loyola.

Gendron, Y., \& Baker, C. R. (2005). On interdisciplinary movements: the development of a network of support around Foucaultian perspectives in accounting research. European Accounting Review, 14(3), 525-569. doi: 10.1080/09638180500041364

Gendron, Y., \& Bédard, J. (2001). Academic auditing research: an exploratory investigation into its usefulness. Critical Perspectives on Accounting, 12(3), 339-368. doi: 10.1006/cpac.2000.0429

Gill, R. (2002). Análise de discurso. In M. W. Bauer \& G. Gaskell (Eds.), Pesquisa Qualitativa com Texto, Imagem e Som (2a ed., pp. 244-270). Petrópolis: Vozes.

Glynos, J., \& Howarth, D. (2007). Logics of critical explanation in social and political theory. London: Routledge.

Humphrey, C., \& Gendron, Y. (2015). What is going on? The sustainability of accounting academia. Critical Perspectives on Accounting, 26, 47-66. doi: 10.1016/j.cpa.2014.09.008

Instituto Brasileiro de Geografia e Estatística. (2016). População residente enviada ao Tribunal de Contas da União. Recuperado em 23 de fevereiro, 2016, de ftp://ftp.ibge.gov.br/Estimativas_de_Populacao/ Estimativas_2015/serie_2001_2015_TCU.pdf

Jeanjean, T., \& Ramirez, C. (2009). Back to the origins of positive theories: a contribution to an analysis of paradigm changes in accounting research. Accounting in Europe, 6(1), 107-126. doi: $10.1080 / 17449480902896510$

Kuhn, T. S. (1998). A estrutura das revoluções científicas. (B. V. Boeira \& N. Boeira, Trads.) (5a ed.). São Paulo: Perspectiva.

Martins, E. A. (2012). Pesquisa contábil brasileira: uma análise filosófica. Tese de Doutorado em Controladoria e Contabilidade, Universidade de São Paulo, São Paulo, SP, Brasil.

Sikka, P., Willmott, H., \& Puxty, T. (1995). The mountains are still there: accounting academics and the bearings of intellectuals. Accounting, Auditing \& Accountability Journal, 8(3), 113-140. doi: $10.1108 / 09513579510094723$

Theóphilo, C. R., \& ludícibus, S. de. (2005). Uma análise crítico-epistemológica da produção científica em contabilidade no brasil. Contabilidade, Gestão e Governança, 8(2), 147-175.

Wilkinson, B. R., \& Durden, C. H. (2015). Inducing structural change in academic accounting research. Critical Perspectives on Accounting, 26, 23-36. doi: 10.1016/j.cpa.2014.03.002 